\title{
TAHSP:
}

The Internet Joưnal of Allied Health Sciences and Practice

A Peer Reviewed Publication of the College of Health Care Sciences at Nova Southeastern University

Dedicated to allied health professional practice and education

http://ijahsp.nova.edu Vol. 12 No. 4 ISSN 1540-580X

\section{"Finishing Business" The Important Role of the Psychosocial Worker in the Interdisciplinary Palliative Care Team: A Hypothetical Case}

\author{
Merridy Rowe, BASW MA Counselling (Research) ${ }^{1}$ \\ Catherine Turnbull, MPA, Post Grad Cert PS Mgmt, BSW2
}

1. Clinical Lead Social Work, Restorative Care, Country Health South Australia, Mount Gambier, South Australia

2. Chief Allied and Scientific Heath Advisor, Office of Professional Leadership, Department of Health and Ageing, Adelaide,

South Australia

\section{Canada}

CITATION: Rowe M, Turnbull C. "Finishing Business" The Important Role of the Psychosocial Worker in the Interdisciplinary Palliative Care Team: A Hypothetical Case. The Internet Journal of Allied Health Sciences and Practice. July 2014. Volume 12 Number 4.

\begin{abstract}
The assessment of the palliative client and family caregivers by an interdisciplinary team comprising medical, nursing, and allied health allows for all aspects including the physical, social, and psychological and spiritual needs to be incorporated into care planning. This comprehensive level of planning for the care of the client and family caregivers can allow for a client to fulfil their own definition of a good death, or dying well. Whilst the provision of psychosocial support can be the seen as the role of the social worker in the team, all members of the palliative care team, especially in rural and remote areas with fewer members, will at times face a situation where they need to provide some psychosocial support. It is acknowledged by the authors that the social work professional identity, responsibilities, and skills are not easily understood, and this identity is further challenged with the prospect of interdisciplinary work. This paper describes and illustrates the psychosocial considerations for the palliative client and family caregiver and has been developed following a review of the definition of a "good death" in consultation with rural and remote-based palliative care team members in South Australia. A literature search of the skills of the social work trained professional applicable to interdisciplinary palliative care work is included. A workforce evidence-based (WEB) diagrammatic tool is offered to illustrate the areas for assessment and intervention. Tasks associated with the psychosocial service to the client and family caregivers, the members of the palliative care team, and the community are defined with the goal of developing a consistent expectation of the role. The contribution of the psychosocial worker in assessing the need for ongoing bereavement support and provision is included.
\end{abstract}

\section{INTRODUCTION}

The South Australian Department for Health and Ageing developed a Palliative Care Service Plan ${ }^{1}$ in line with the South Australia's Health Care Plan. ${ }^{2}$ The Palliative Care Service Plan held the joint service delivery philosophies of a skilled interdisciplinary team, defined as one, offering services to the client and their family caregivers and embracing client centred care. ${ }^{3}$ The Palliative Care Service Plan aligned with the World Health Organization definition of palliative care:

"an approach that improves the quality of life of patients and their families facing the problem(s) associated with life-threatening illness, through the prevention and relief of suffering by means of early identification and impeccable assessment and treatment of pain and other problems - physical, psychosocial and spiritual" 4 
The Palliative Care Services Plan identified a goal to assist clients to choose their place of death and for palliative care teams to be adapted to support this choice recognizing that many people choose to die at home. In order for palliative care teams to address both the assessment and treatment of pain and other problems - physical, psychological, and spiritual, the development of interdisciplinary teams described as "a partnership between a team of health professionals and a client in a participatory, collaborative \& co-ordinated approach to shared decision-making around health issues" were identified. ${ }^{5}$

Many South Australian rural and remote palliative care teams have historically consisted of a nurse with some bereavement support. Medical support has been provided by general practitioners with support from a visiting palliative specialist travelling from metropolitan Palliative Care services. The rural and remote palliative care teams have employed a number of variously trained professionals - pastoral care workers, social workers, and others with counseling training in order to address the psychosocial and spiritual aspects of care. With the focus of palliative care moving towards an interdisciplinary approach, the tasks associated with the psychosocial aspects of care of the client and the family caregiver may be addressed by any member of the team.

\section{The Palliative Approach}

Initially, the modern palliative approach was associated with care of patients dying from cancer-related illnesses. Palliative care involved patients being cared for in a hospital ward or separate hospice facility by nursing and medical staff. Palliative care service has evolved and is available to any person facing a life limiting illness. The focus of palliative service has moved towards client empowerment and choice about the site of care. As palliative care has evolved to a definition of "dying my own way,"6 the medical, nursing, and allied health disciplines have been challenged to develop a process to assist a client to fulfill their own definition of a good death, or dying well, or living well until death. ${ }^{7}$

The Therapeutic Guidelines Palliative Care suggests that whilst it is impossible to assign a set of universal values to dying, "there is a general agreement that good symptom control, clear decision-making, good preparation for dying, and a sense of completion are important for most individuals." 8 Chan refers to two composite scales that represent physical and psychosocial indicators of good death that is physically pain-free on the one hand and psychologically at peace and with positive feelings toward family on the other. ${ }^{9}$ Pallipedia defines a decent or good death as typically defined as one that is free from avoidable distress and suffering for patients, families and caregivers. ${ }^{10}$

\section{Finishing Business}

Social work has historically struggled with the difficulty of illustrating the profession's area of expertise. This difficulty itself is reflected in the health care team's poor understanding of the capacity of a social worker to deliver a therapeutic service. Sheldon, Meier and Beresford, Orchard et al, Christ and Blacker, and Lloyd all refer to the lack of appreciation by team members of the skills the social worker can contribute to the realm of clinical counselling and therapeutic intervention., $511,12,13,14$ This difficulty can be exacerbated where other members of the palliative care team, for example nursing staff, may frequently be who the palliative client turns to with their emotional reaction to their prognosis or to ask for advice and assistance to deal with the implications of the disease trajectory.

A therapeutic intervention example is that of Dr. Chochinov et al who developed Dignity Therapy to address the psychosocial and existential distress among the terminally ill. ${ }^{15}$ The therapy allows the client to address aspects of their life that they feel are most important or meaningful for them and things that need to be said. It has components that address grief-related issues. Themes associated with Dignity Therapy and recognised as important to a client experiencing a good death relate to being empowered to make informed decisions about health care, completing unfinished business with family, and leaving a legacy. Similar work by Steinhauser et al focuses on the preparation for life completion and incorporates aspects of reflection, recording of a life story, seeking and granting forgiveness, and leaving a legacy. 16

Literature also refers to other skills of social work such as that of team leader, program manager or administrator, expert knowledge in navigating the medical system, and advocating for the client at the organizational level. ${ }^{17}$ These tasks all contribute to client centred practice of palliative care. Social workers can be key workers in the empowerment for the client and family caregivers and in guiding interdisciplinary teams to the consumer choice service delivery philosophy.

Further, the social worker has a role in initiating or participating in research and training relevant to end-of-life care..$^{13}$ The National Association of Social Workers discusses the broad range of experience and skills of the social worker especially those associated with promoting culturally competent, effective and humane care. ${ }^{18}$ Finally, Vachon in Rezenbrink focus on the social work role in recognising, managing, and developing organisational structures to support the caregiver stress of staff in palliative care. ${ }^{19}$ The social worker can contribute a broad range of knowledge, skills, and expertise to the client and family caregivers, the

(c) The Internet Journal of Allied Health Sciences and Practice, 2014 
interdisciplinary palliative care team members, the health organisation, and the community and can contribute to the body of knowledge relating to the psychosocial aspect of care.

The Clinical Practice Guidelines for the psychosocial and bereavement support of family caregivers of palliative care patients outlines the core work of the therapist being an assessment of the need for support services and assessing risk for poor bereavement outcomes. ${ }^{20}$ In metropolitan-based or larger palliative care teams, the tasks associated with supporting the client can be assigned to one worker and another worker may take on the bereavement support of the family caregivers after the death of the client. In rural and remote palliative care teams, the psychosocial worker needs to provide support to the client and the family caregivers, both at the time of the referral to palliative care and after the death of the client.

The interface between the social worker and the bereavement support worker roles in the smaller rural and remotely-based palliative care teams has been unclear and ill defined. Some working in the bereavement counsellor role have defined their tasks as delivering the therapeutic intervention leaving the other tasks such as navigation of the health system and practical support to the social worker. This has led to a perception that social work focuses solely on these tasks and does not incorporate the full scope of therapeutic intervention.

Many of the psychosocial workers in rural and remote teams are not employed on a full time basis in the palliative care team. Interdisciplinary meetings may need to be held without the full representation of the team. This factor has significant impact on interdisciplinary practice. ${ }^{21}$ In an optimal functioning interdisciplinary team, there is consideration of the assessment by every discipline in order to provide an integrated service.

\section{The Development of the Conceptual Diagram}

The conceptual diagram represents the tasks of the psychosocial worker in a palliative care team and was developed following a literary search focussing on a definition of "good death." It is a development of the work of Leach and Segal's Workforce Evidence Based (WEB) model for chronic disease.22 The diagram aims to raise the awareness of the contribution of the role to a comprehensive service delivery model.

The conceptual diagram was drafted and distributed to palliative care team members and line managers employed across rural and remote South Australia, and comments were incorporated and the diagram redistributed. The revised conceptual framework was presented at a meeting for the team leaders of palliative care teams in rural and remote locations in South Australia. The feedback led to further development with aspects relating to non-client specific tasks such as contribution to research, education and empowerment of community resources, and the team support role. The consultation process also led to the role of the support worker who works with the carers after the death of the client being included beyond the circumference of the diagrammatic model. The diagram was offered for consideration to senior social workers in the metropolitan region of South Australia for comment, and their feedback suggested that a similar document did not exist in the metropolitan region for comparison.

\section{The "Slices" within the Diagram}

The framework incorporates the WHO palliative care definition where the service of palliative care is to improve the quality of life of clients and family caregivers (represented by the first and second inner circles). The third circle represents the ongoing assessment process of palliative care to monitor the level of need for psychosocial intervention and support. The concentric circles represent an outward moving focus from the client and their family caregivers to the interface of palliative care with appropriate community resources.

The framework illustrates the aspects of social and psychological care delivery in "slices" named to identify key foci for intervention. They encompass aspects during the palliative phase and after the death of the client. Incorporated are responsibilities and roles that aim to build community capacity and resilience in the management of the psychosocial aspects of loss and grief. A further "slice" represents collaborative work in education and research. 
Figure 1. Psychosocial Worker Role in Palliative Care

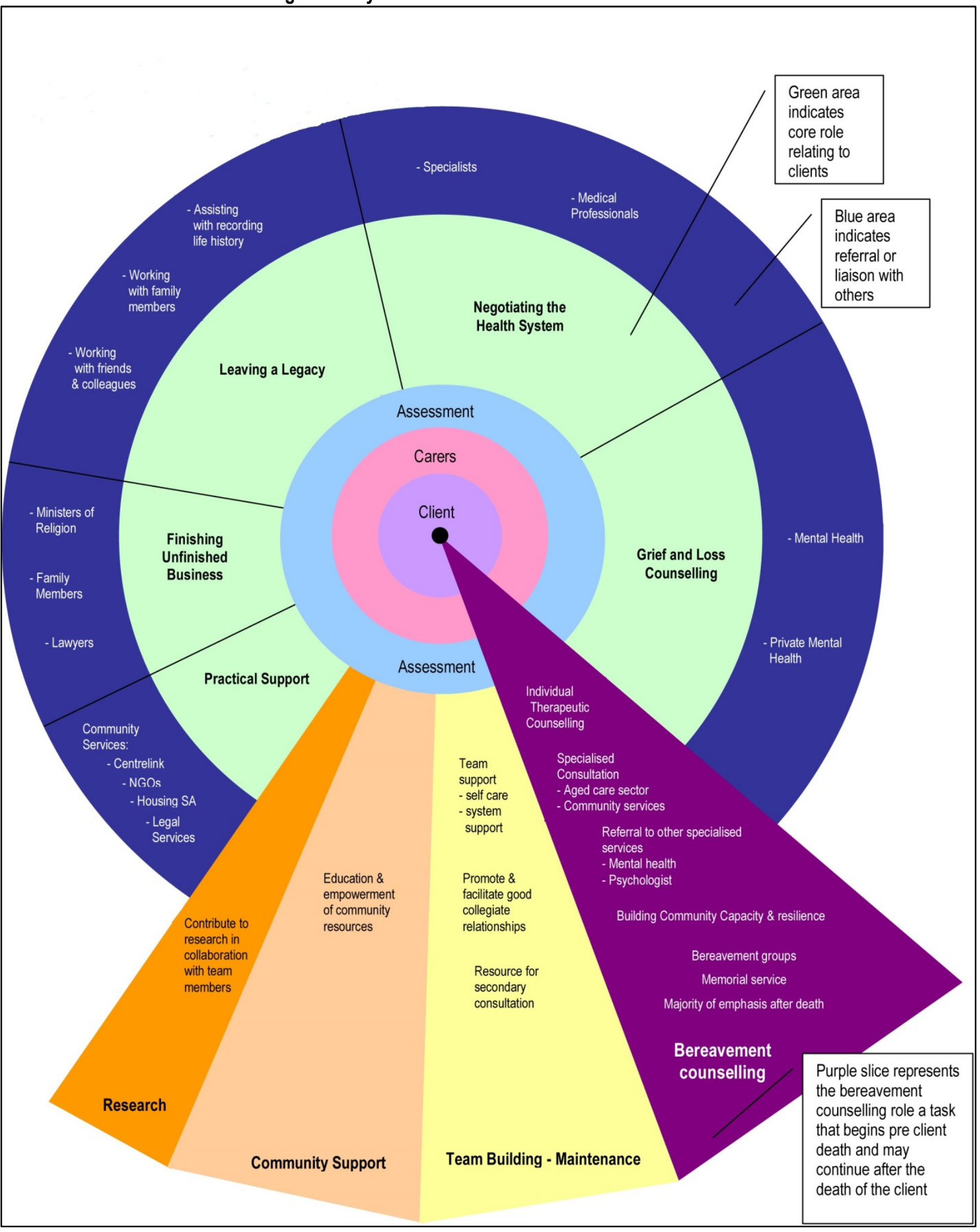

The tasks associated in the "slices" of services provided directly to clients and carers are listed below in Table 1. 
Table 1

\begin{tabular}{|c|c|}
\hline Practical help & $\begin{array}{l}\text { - Key worker role with assigned clients and their family caregivers. } \\
\text { - Co-joint worker role with other team members. } \\
\text { - Utilising assessment tools in order to assist the team to assist the client and family } \\
\text { caregiver (carer stress index, mini mental, depression scale, genogram, ecomap } \\
\text { etc.) } \\
\text { - Providing information and support in accessing both health based and community } \\
\text { based services } \\
\text { - Providing information and support in accessing legal and financial information } \\
\text { including carer allowances. } \\
\text { - Reassuring the client of the follow up to family caregivers after the death of the client } \\
\text { - to assess bereavement risk and offer indicated on-going support. } \\
\text { - Providing loss and grief counselling as indicated and to make referrals to other } \\
\text { - } \text { Suitable community based services. } \\
\text { - } \text { Srganizing and running of support groups (in association with the other community } \\
\text { - Arranging for a community based Memorial or Remembrance or Celebration Service. }\end{array}$ \\
\hline $\begin{array}{l}\text { Negotiating } \\
\text { the health } \\
\text { system }\end{array}$ & $\begin{array}{l}\text { - Empowering and facilitating the client and their family caregivers to liaise with } \\
\text { specialists/nursing and medical staff to clarify medical options. } \\
\text { - Discussion of and assistance to formalise end of life choices } \\
\text { - Organising, chairing and recording family meetings and case conferences. }\end{array}$ \\
\hline $\begin{array}{l}\text { Reviewing/finish } \\
\text { unfinished business }\end{array}$ & $\begin{array}{l}\text { - Assisting the client and their family caregivers to achieve desired outcomes with a } \\
\text { problem-solving approach. } \\
\text { - Referral or liaison with pastoral care providers, family caregivers and /or legal } \\
\text { professionals in order to address unfinished business (address old disputes, } \\
\text { estrangements, finalising relationships). }\end{array}$ \\
\hline Leaving a legacy & $\begin{array}{l}\text { - Working with the client and their family caregivers to assist the client to record their } \\
\text { life history and leave a legacy of their life (letters to family members, video } \\
\text { recordings, scrapbooking/photo albums etc). }\end{array}$ \\
\hline $\begin{array}{l}\text { Grief and loss } \\
\text { counselling }\end{array}$ & $\begin{array}{l}\text { - To assess the risk of complex or prolonged grief of family caregivers. } \\
\text { - To assist clients and their family caregivers to discuss the implications of the life- } \\
\text { limiting illness and explore and validate the emotions associated with the pain of the } \\
\text { loss. } \\
\text { - To assist clients and family caregivers to understand the extent of normal physical, } \\
\text { emotional, thoughts and behaviours associated with loss and grief reactions. } \\
\text { - To work with clients and family caregivers on strategies to manage the pain of loss } \\
\text { and grief } \\
\text { - to offer an indicated therapeutic service and to make referrals to other indicated } \\
\text { services (mental health team, psychiatrists, psychologists) }\end{array}$ \\
\hline Community & $\begin{array}{l}\text { - Building links with community services to educate and support the provision of loss } \\
\text { and grief counselling } \\
\text { - Participate in educating community members and service providers about the } \\
\text { palliative approach in life limiting illness. }\end{array}$ \\
\hline Team support & $\begin{array}{l}\text { - To lead in association line managers the focus on selfcare strategies for palliative } \\
\text { - Pare workers. } \\
\text { in the community. } \\
\text { - Act as a specialist consult to other team members and community resources in } \\
\text { relation to palliative care and loss and grief issues. } \\
\text { - Contribute to the training, support, task assignment and management of volunteers } \\
\text { to the palliative care team }\end{array}$ \\
\hline Research & $\begin{array}{l}\text { - Contribute to well designed and structured studies that advance the quality of care of } \\
\text { palliative clients and the carers. }\end{array}$ \\
\hline
\end{tabular}




\section{Working with Ms. F}

This case study of a hypothetical client and family caregivers illustrates the application of the tasks of the psychosocial worker. Ms. F had been diagnosed with Motor Neurone Disease and referred to the Palliative Care team. She was experiencing difficulties with speech and swallowing and some left leg weakness. She lived at home with her husband and two teenage children. Her husband worked full time and needed to travel interstate on a regular basis. The teenage children had not been made aware of their mother's prognosis and their mother was struggling with the implications of her diagnosis.

At the palliative care interdisciplinary meeting, the psychosocial support worker recognised a role was needed to assist the family with the implications of the mother's diagnosis and arranged to attend the home with a nurse member of the team. At this home visit, the nurse and psychosocial support worker were together able to clarify the possible course of the disease and highlight some of the decisions relating to mobility, speech, and nutrition which may be required in the future. Information was provided on websites that Ms F and her family members could access for information and support relating to the disease.

The psychosocial support worker met with both Mr and Ms F for discussions relating to end-of-life decisions, medical authorities, and other practical issues relating to family income and funeral arrangements. Information relating to options for supports available for in home care was offered.

The psychosocial support worker enlisted the help of both Ms F and her husband to create a genogram of the family and this led to discussions about possible options for Ms F to consider about leaving a legacy for her children including letters for future birthdays and significant events. The worker was also able to collect information in this process which enabled her to assess the risk for complex and prolonged grief response for each member of the family.

An ecomap (mindmap) was created with Ms F and a picture of the supports and interests for Ms F. The psychosocial support worker was able to work with other interdisciplinary team members to create a plan to assist Ms F to maintain her contact and interests as her health declined.

The couple discussed strategies with the worker to advise their teenage children and other family members about the situation for Ms F. The worker offered to meet with family members on an individual basis for loss and grief counselling.

The psychosocial support worker met with Ms F and other members of the family on an individual basis during the course of her illness both to assess how each family member was managing the anxiety and stress and to provide counselling and strategies to manage the psychosocial and spiritual issues relating to their situation. The family also agreed to invite the priest to assist them during this time. The worker continued to meet with the husband and children following the death of Ms F and worked with the family as they dealt with their loss and linked them with other supports in their community.

\section{Living Well While Finishing Business}

This paper has considered the aspects of service delivery that can be offered by the psychosocial worker in the interdisciplinary palliative care team in order to assist the client and the family caregiver to experience a "good death." In smaller teams like those in rural and remote South Australian locations, the aspects of psychosocial support may need to be delivered by all members of the interdisciplinary team. The WEB based diagram can be utilised to assist in the development of all aspects of the psychosocial worker in line with the philosophy of a "good death." It can be used to assist all staff and students to envisage the aspects of the contribution of the worker employed in the psychosocial role and can be used to assist interdisciplinary collaborative work.

The diagram can be used to assist in the employment of appropriately skilled and experienced staff. It is envisaged that it will lead to a consistent expectation of the roles, tasks, skills, and expertise of the role, and that job and person specifications will be developed that incorporate these ideas. The diagram is an evolving tool and is offered for consideration by the social work, nursing, medical, and allied health professions.

The vision of delivering a consistent palliative care service to rural and remote clients as well as those in larger metropolitan areas remains a service delivery challenge. As funding becomes available to build rural and remote palliative care teams, there will need to be consideration of the role and contribution of other allied health, nursing, and medical staff to the interdisciplinary team.

Through the use of this framework, the Palliative Care Team can consider the various roles and resources available to provide services and therapy to clients and family caregivers. This can assist palliative care teams with a more flexible approach to

(c) The Internet Journal of Allied Health Sciences and Practice, 2014 
establishing a team and then maintaining good working relationships between team members. The outcome of such flexibility should be a strong cohesive palliative care team that contributes to supporting bereaved family caregivers, educating the community, leaving a legacy, finishing business and most importantly enables the fulfilment of the client's aim of living well until death.

\section{REFERENCES}

1. Government of South Australia Department of Health South Australia. Palliative Care Services Plan 2009- 2016. 2009. http://www.health.sa.gov.au/Portals/0/palliative-care-plan-2009-2016.pdf, Accessed June 1, 2014.

2. Government of South Australia Department of Health. South Australia's Health Care Plan 2007-2016.2007. http://www.sahealth.sa.gov.au/wps/wcm/connect/893b1180428de54db565b7e7eece1070/sahcp-sahealth20072016.pdf?MOD=AJPERES\&CACHEID=893b1180428de54db565b7e7eece1070, Accessed June 1, 2014.

3. Crawford GB, Price SD. Team working: palliative care as a model of interdisciplinary practice. Medical Journal of Australia. 2003;179(6 Suppl):S32-4. [PMID:12964934]

4. WHO definition of Palliative Care. World Health Organization 2005, http://www.who.int/cancer/palliative/definition/en/, Accessed June 1, 2014.

5. Orchard CA, Curran V, Kabene S Creating a Culture for Interdisciplinary Collaborative Professional Practice. Med Educ Online [Serial Online]. 2005;10:11.

6. McNamara B. Reflections on Fragile Lives: Death and Dying and Care. Open University Press, Buckingham 2001.

7. Byock I. Dying Well: Peace and Possibilities at the End of Life. The Berkley Publishing Group. New York. 1997.

8. Farrington C. Palliative Care Expert Group. Therapeutic Guidelines Palliative Care. Version 3. Melbourne: Therapeutic Guidelines Limited; 2010. BMJ Support Palliat Care. 2011 Apr 15. doi: 10.1136/bmjspcare-2011-000032. [Epub ahead of print] [PMID:24644158]

9. Chan WC, Epstein I, Reese D, Chan CL. Family predictors of psychosocial outcomes among Hong Kong Chinese cancer patients in palliative care: Living and dying with the "support paradox". Social Work in Health Care. 2009;48(5):519-32. [PMID 19806711]

10. Pallipedia free on-line palliative care dictionary. www.pallipedia.org.

11. Sheldon FM. Dimensions of the role of the social worker in palliative care. Palliative Care Medicine. 2000;14(6):491-8. [PMID:11219879]

12. Meier $D E$, Beresford $L$. Palliative care professionals contribute to state legislative and policy initiatives. Journal of Palliative Medicine. 2008;11(8):1070-3. doi: 10.1089/jpm.2008.9849. [PMID:18980444]

13. Christ GH, Blacker S. Series introduction:The profession of social work in end-of-life and palliative care. J Palliat Med. 2005 Apr;8(2):415-7. [PMID:15890052]

14. Lloyd M Dying and Bereavement, Spirituality and Social Work in a Market Economy of Welfare. British Journal of Social Work. 1997;27:175-90.

15. Chochinov HM, Krisjanson LJ, Hack TF, Hassard T, McClement S, Harlos M. Dignity in the terminally ill: revisited. J Palliat Med. 2006 Jun;9(3):666-72. [PMID:16752972]

16. Steinhauser KE, Alexander SC, Byock IR, George LK, Tulsky JA.Seriously ill patients' discussions of preparation and life completion: an intervention to assist with transition at the end of life. Palliat Support Care. 2009 Dec;7(4):393-404. doi: 10.1017/S147895150999040X.PMID:19939302

17. Gregorian C. A career in hospital social work: do you have what it takes? Soc Work Health Care. 2005;40(3):1-14. [PMID:15837665]

18. National Association of Social Workers. NASW Standards for Palliative and End of Life Care 2004. http://www.socialworkers.org/practice/bereavement/standards/standards0504New.pdf, Accessed June 1, 2014.

19. Vachon M. Four decades of selected research in hospice/ palliative care: have the stressors changed? In Renzenbrink I, eds. Caregiver Stress and Staff Support in IIIness, Dying and Bereavement. Oxford University Press, 2011.

20. Hudson P, Remedios C, Zordan R, Thomas K, Clifton D, Crewsdon M, Hall C, Trauer T, Bolleter A, Clarke D. Clinical Practice Guidelines for the Psychosocial and Bereavement Support of Family Caregivers of Palliative Care Patients. Centre for Palliative Care, St Vincent's Hospital Melbourne: Melbourne, Australia 2010.

21. Reeves S, Lewin S. J Interprofessional collaboration in the hospital: strategies and meanings. Health Serv Res Policy. 2004 Oct;9(4):218-25. [PMID:15509407]

22. Leach MJ, Segal L. Are clinical practice guidelines (CPGs) useful for health services and health workforce planning? A critique of diabetes CPGs. Diabetic Medicine. 2010;27:570-7. 